WMU Journal of Maritime Affairs, Vol. 7 (2008), No.1, 109-131

\title{
Risk Analysis for RoPax Vessels
}

\author{
Dimitris Konovessis, Dracos Vassalos and George Mermiris \\ Universities of Glasgow and Strathclyde
}

\begin{abstract}
The paper presents the results of a recent risk analysis study for RoPax vessels, carried out as part of the activities of the SAFEDOR Integrated Project. The objective of this study was to investigate the causes of hazards during RoPax operation and quantify, to the extent possible, their frequencies and consequences. Potential scenarios initially identified and prioritised during a Hazard Identification (HAZID) session were used in the process.

The work has been performed in accordance with the IMO FSA Guidelines (IMO 2002). A previous comprehensive study on the safety assessment of RoPax vessels sailing in North West European waters, covering the period until 1994, was used as the basis in putting together a high-level risk model for the current study. All scenarios are presented in the form of event trees, quantification of which is done on the basis of world-wide accident experience (from 1994 to 2004), relevant past studies and judgment. The study estimates the risk of loss of life among passengers and crew (by calculating for each scenario the Individual Risk, the Potential Loss of Life-PLL and plotting the corresponding F-N curves), and compares them with current risk acceptance criteria. The resulting high-level risk model is used to provide recommendations for improvement in the form of proposed risk control options (RCOs).
\end{abstract}

Key words: Marine Accident Analysis, Formal Safety Assessment, Risk Acceptance Criteria

\section{Introduction}

The overall scope of this high-level, generic risk analysis study is to investigate credible accident scenarios of a certain scale that may occur during RoPax operations. Occupational hazards that would affect individual members of the crew and passengers' personal accidents, such as slips and falls, have not been included in the study. The following operational phases, as considered during a HAZID session, provide the range that is taken into account in performing this study:

- Loading;

- Departing quay;

- Transit and navigation in coastal waters;

- Transit in open sea;

Lecturer, Professor, Research Fellow, The Ship Stability Research Centre, Universities of Glasgow and Strathclyde, 100 Montrose Street, Glasgow G4 0LZ, United Kingdom, emails: \{d.konovessis; d.vassalos; g.mermiris\}@na-me.ac.ukk

(c) World Maritime University. All rights reserved. ISSN: 165I-436X print//654-1642 online 
- Arriving at port, mooring and preparing for unloading;

- Unloading

In this respect, no analysis has been carried out for accident scenarios that may occur during construction, sea-trials, dry docking, repairs and scrapping, as well as for security hazards.

\section{Safety Regulations}

The main consequences on a RoPax following an accident may be graceful sinking or capsize and/or fire which can result in great loss of life among the passengers and crew onboard. Some of IMO's regulations are particularly relevant to RoPax operations and are briefly outlined in the following under the headings: subdivision and damage stability; fire safety; and implementation of the International Safety Management (ISM) Code.

\subsection{Subdivision and Damage Stability (SOLAS Chapter II-1)}

Currently the global standard for damage stability of RoPax ships is the vessel to be able to sustain any two-compartment damage and also fulfilling a set of deterministic requirements known as SOLAS 90. This represents a significant improvement with the standards applicable at the beginning of 1990s and is in general considered a sufficient and satisfactory standard. In North West Europe, an increased standard is applied for existing ships, known as the "Stockholm Agreement" or SOLAS 90+50, which requires either fulfillment of the deterministic standards of SOLAS 90 with an additional height of water on deck (maximum of $50 \mathrm{~cm}$ ), or the demonstration by means of model experiments that the vessel can survive in damaged conditions the sea state at the area of operation.

The IMO's Sub-Committee on Subdivision, Load Lines and Fishing Vessel Safety (SLF) has developed a new set of probabilistic rules for all ship types for global application from 2009 onwards. These rules follow the approach developed at Resolution A.265 (IMO issued this resolution at 1974, as an alternative to the deterministic SOLAS damage stability requirements) and are mainly based on extensive research work carried out at the late 1990s/early 2000s as part of the activities of the EC-funded research project HARDER.

\subsection{Fire Safety (SOLAS Chapter II-2)}

To accommodate novel designs and issues relating to the human element, the IMO Sub-Committee on Fire Protection undertook an 8-year effort that led to the adoption of an entirely new structure for SOLAS Chapter II- 2 which may better accommodate the way port and flag states and ship designers would deal with fire safety issues in the future.

The new structure focuses on the "fire scenario process" rather than on ship type, as the current SOLAS Chapter II- 2 is structured. Thus, the regulations start with prevention, detection, and suppression following all the way through to escape. In addition, to make the revised SOLAS Chapter II-2 more user-friendly, specific system related technical 
requirements were moved to a new International Fire Safety Systems (FSS) Code and each regulation will now have a purpose statement and functional requirements to assist port and flag states in resolving matters which may not be fully addressed by prescriptive requirements.

The revised SOLAS Chapter II-2 also has a new Part E that deals exclusively with human element matters such as training, drills and maintenance issues and a new Part F that sets out a methodology for approving alternative (or novel) designs and arrangements. With regards to the latter, the regulations contained in Part F will be supported by a new set of guidelines. The new guidelines, once adopted, are intended to provide technical justification for alternative design and arrangements to SOLAS Chapter II-2. The guidelines will outline the methodology for the engineering analysis required by the new SOLAS Regulation II-2/17, dealing with alternative design and arrangements, where approval of an alternative design deviating from the prescriptive requirements of SOLAS Chapter II-2 is sought.

The revised SOLAS Chapter II- 2 and the associated FSS Code entered into force on 1 July 2002 and will apply to all ships built on or after 1 July 2002, although some of the amendments apply to existing ships as well as new ones.

\subsection{ISM Code (SOLAS Chapter IX)}

The ISM Code was adopted by the 1993 Assembly at IMO as Resolution A.741(18). The ISM Code is made mandatory for all SOLAS ships, regardless of their year of construction.

The Code requires a Safety Management System (SMS) to be established by the shipowner or manager to ensure compliance with all mandatory regulations and that codes, guidelines and standards recommended by IMO and others are taken into account. Companies are required to prepare plans and instructions for key shipboard operations and to make preparations for dealing with any emergencies which might arise. The importance of maintenance is stressed and companies are required to ensure that regular inspections are held and corrective measures taken where necessary. The procedures required by the ISM Code should be documented and compiled in a Safety Management Manual, a copy of which should be kept onboard. Regular checks and audits should be held by the company to ensure that the SMS is being complied with and the system itself should be reviewed periodically to evaluate its efficiency. The ISM Code is being applied on RoPax ships since July 1998.

\section{Reference Data}

\subsection{World RoPax Fleet}

Table 1 shows the number and size distribution of the RoPax fleet world-wide, as of March 2006, according to Lloyds Register - Fairplay (LRFP) data.

A first observation is that a big percentage of the fleet (42.2\%) is ships of 1,000 GRT and below. The development of the fleet over the period 1994-2004 is illustrated in Figure 1. 
Figures 2 and 3 illustrate the age distribution of RoPax ships. It can be deducted from these two graphs that newer ships are usually of bigger tonnage.

Finally, Table 2 shows the distribution of the maximum carrying passenger capacity of 1,153 RoPax vessels.

\subsection{Data Used}

To carry out the risk analysis study for RoPax a set of reference, generic data should be considered. As illustrated in Section 3.1 the distribution of sizes of the RoPax fleet is wide, hence it is considered that by selecting a RoPax ship with specific characteristics would greatly limit the scope of the study. Hence, the following considerations/ assumptions are made:

- RoPax ships of 1,000 GRT and below, are usually engaged on short crossings and passages and are often of an open-type configuration. A representative RoPax for a generic risk analysis study should be of a closed-type configuration and part of her trip is usually exposed to weather. On this basis, all RoPax ships of 1,000 GRT and below are excluded from this study.

- To distinguish between small and larger RoPax ships, two categories are initially considered: one of 1,000 to 4,000 GRT and one of 4,000 GRT and above. The purpose for this consideration is to investigate differences on accidents frequencies between small and larger RoPax.

- The distribution of number of passenger of Table 2, reproduced from (Kanerva 2001), indicates an average maximum carrying capacity of around 1,000 passengers.

In carrying out risk estimations for Individual Risk, Potential Loss of Life (PLL) and producing the F-N diagram plot, the following assumptions are made:

- Different traffic loads indicate great fluctuations on the number of passengers carried, depending on the period of the year. Taking into account the average maximum carrying capacity of 1,000 passengers, traffic seasonality is assumed as follows:

$-25 \%$ of trips carrying full passenger load (1,000 passengers)

$-25 \%$ of trips carrying half of maximum passenger load (500 passengers)

- 50\% of trips carrying $75 \%$ of maximum passenger load (750 passengers)

- Crew onboard a RoPax is usually between 75 and 120. For the purpose of this study, crew number of 100 is considered as an average.

\section{$4 \quad$ Risk Criteria}

In this section, risk criteria that will be used are outlined. A review of risk evaluation criteria has been carried out in another SAFEDOR task and is reported in (SAFEDOR 2005), making use of previous work reported in (IMO 2000). In the following acceptance criteria for individuals (crew and passengers) and for the whole group of people (societal criteria) onboard a RoPax are discussed. 
Table 1. Current RoPax Fleet, world-wide data, March 2006

\begin{tabular}{|c|c|c|c|c|c|c|c|c|}
\hline $\begin{array}{c}\text { GRT } \\
\text { Ranges }\end{array}$ & $\begin{array}{c}\text { Convert- } \\
\text { ing/ Re- } \\
\text { building }\end{array}$ & $\begin{array}{c}\text { In } \\
\text { Casualty/ } \\
\text { Repairing }\end{array}$ & $\begin{array}{c}\text { In } \\
\text { Service/ } \\
\text { Com- } \\
\text { mission }\end{array}$ & Laid Up & $\begin{array}{c}\text { To be } \\
\text { Broken } \\
\text { Up }\end{array}$ & $\begin{array}{c}\text { Uncon- } \\
\text { firmed } \\
\text { Ships }\end{array}$ & $\begin{array}{c}\text { New } \\
\text { Con- } \\
\text { struction }\end{array}$ & Total \\
\hline $\begin{array}{c}\text { Up to } \\
1,000\end{array}$ & 2 & 4 & 1,163 & 8 & 2 & 0 & 17 & 1,196 \\
\hline $\begin{array}{c}1,000 \\
\text { to } \\
4,000\end{array}$ & 0 & 8 & 656 & 7 & 0 & 0 & 16 & 687 \\
\hline $\begin{array}{c}4,000 \\
\text { and } \\
\text { above }\end{array}$ & 1 & 12 & 864 & 6 & 2 & 0 & 65 & 950 \\
\hline \begin{tabular}{c} 
Total \\
\hline
\end{tabular} & 3 & 24 & 2,683 & 21 & 4 & 0 & 98 & 2,833 \\
\hline
\end{tabular}

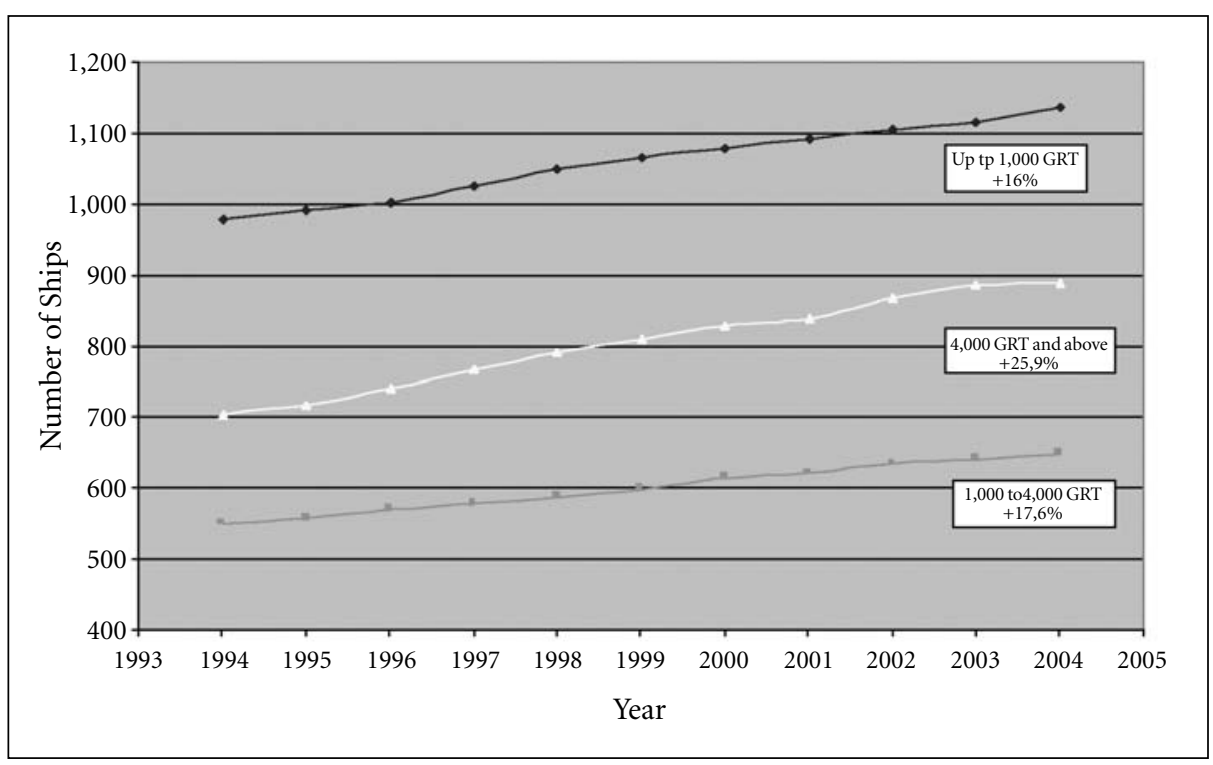

Figure 1. RoPax Fleet development, world-wide data (1994-2004)

\subsection{Individual Risk Criteria}

Individual risk is the risk experienced by a single individual (passenger or member of crew) in a given time period, who, in our case, is exposed to hazards relating to RoPax operations. The individual risk is usually expressed as the frequency of an individual fatality per year.

SAFEDOR (2005) proposes criteria for individual risk for shipping operations at the same level as those used by the UK Health and Safety Executive. These criteria are reproduced in Table 3. On the basis of these criteria, intolerable, ALARP and negligible risk levels for individuals (passengers and crew) are determined. 
In this study, average individual risks are estimated on the basis of potential accident scenarios which form the generic risk model developed. These estimations can then be weighted with different exposure expected for crew members and passengers, in order to determine risk acceptability or not.
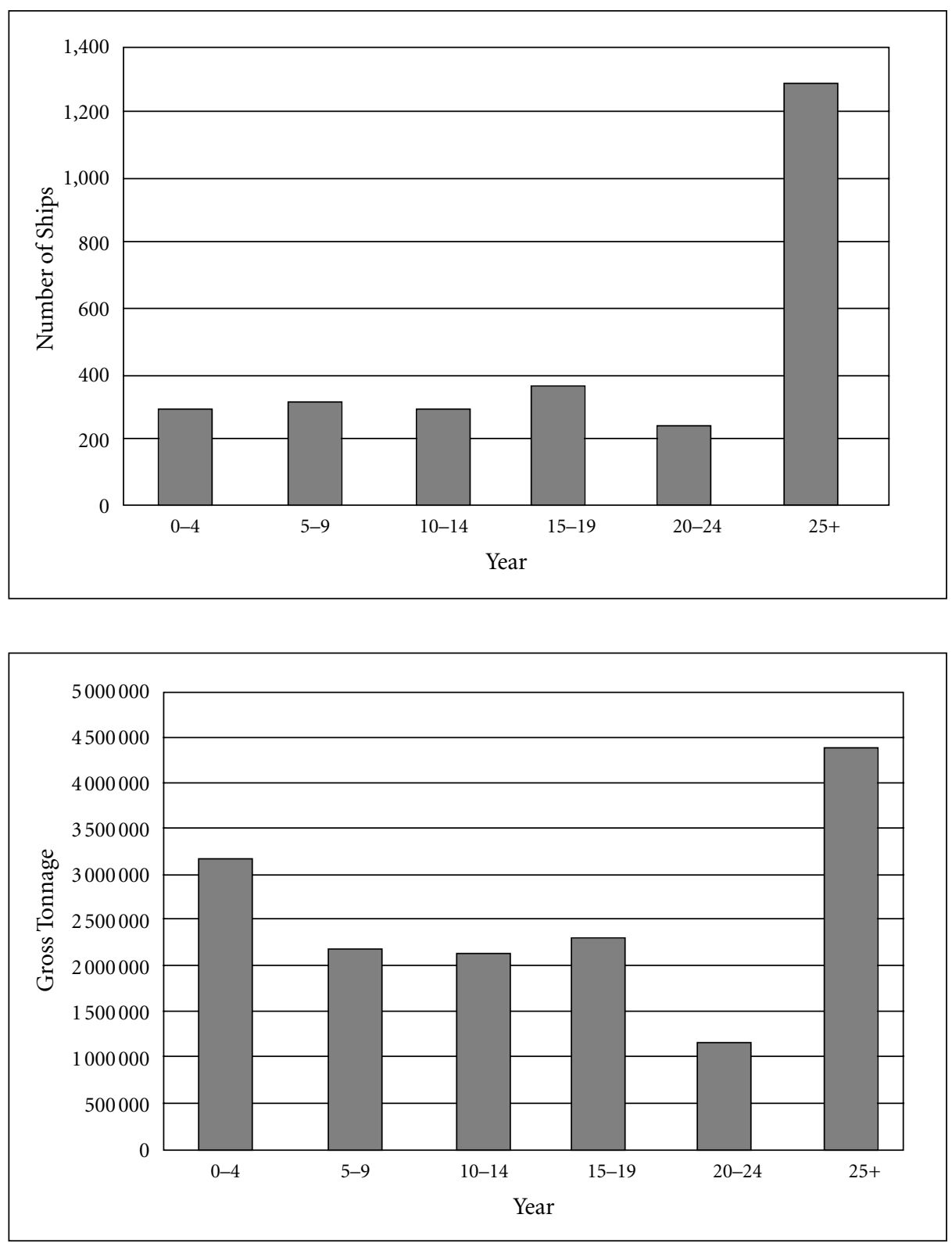

Figure 2 and 3. Age distribution of RoPax Fleet in 2004 
Table 2. World RoPax Fleet - distribution of passenger carrying capacity (2000) - (Kanerva 2001)

\begin{tabular}{|c|c|c|c|c|c|c|}
\hline Group & \multicolumn{7}{|c|}{ Number of Passengers } \\
\hline $\mathrm{L}_{\text {OA }}(\mathrm{m})$ & Below 500 & 500 to 1,000 & $\begin{array}{c}1,000 \text { to } \\
1,500\end{array}$ & $\begin{array}{c}1,500 \text { to } \\
2,000\end{array}$ & Above 2,000 & Total \\
\hline Below 100 & 162 & 192 & 56 & 4 & 1 & 415 \\
\hline $100-120$ & 33 & 67 & 62 & 15 & 7 & 184 \\
\hline $120-150$ & 22 & 93 & 100 & 53 & 23 & 291 \\
\hline $150-180$ & 23 & 49 & 25 & 33 & 31 & 161 \\
\hline Above 180 & 7 & 34 & 26 & 18 & 17 & 102 \\
\hline Total & 247 & 435 & 269 & 123 & 79 & 1,153 \\
\hline
\end{tabular}

\subsection{Societal Risk Criteria}

Societal risk is the total risk experienced by the whole group of people (passengers or crew members) travelling on a ship. It is usually plotted on an F-N log-log diagram which shows the relationship between the cumulative frequency $\mathrm{F}$ of incidents with $\mathrm{N}$ or more fatalities against the number of fatalities $\mathrm{N}$.

Risk criteria on an F-N diagram distinguish intolerable, ALARP and negligible risk areas. The criteria are plotted on the basis of "anchor" points and a selected gradient (usually a slope of -1 is chosen, risk averse). The usual approach is the societal criterion for accidents with 1 death to correspond to the prescriptive individual criterion (also meaning that the anchor points are usually taken at $\mathrm{N}=1$ ). Different activities and industry sectors will require different criteria to reflect the corresponding level of risk considered tolerable.

Table 4 contains the anchor points for societal criteria suggested in SAFEDOR (2005) for RoPax vessels, using anchor points at $\mathrm{N}=10$. That report also states that these criteria have been derived on the basis of economic importance.

Figure 4 illustrated the criteria lines using the anchor points of Table 4 and assuming risk adverse perception (slope of the lines equal to -1 ).

Table 3. Individual risk criteria

\begin{tabular}{|l|c|}
\hline Individual risk criterion & Value \\
\hline Maximum tolerable risk for crew members & $10^{-3}$ per year \\
\hline Maximum tolerable risk for passengers & $10^{-4}$ per year \\
\hline Negligible risk & $10^{-6}$ per year \\
\hline
\end{tabular}


Table 4. Societal criteria for RoPax

\begin{tabular}{|l|c|}
\hline Anchor points for societal criteria & Values \\
\hline Boundary between negligible and tolerable risk & $\left(10,10^{-4}\right)$ \\
\hline Boundary between tolerable and intolerable risk & $\left(10,10^{-2}\right)$ \\
\hline
\end{tabular}

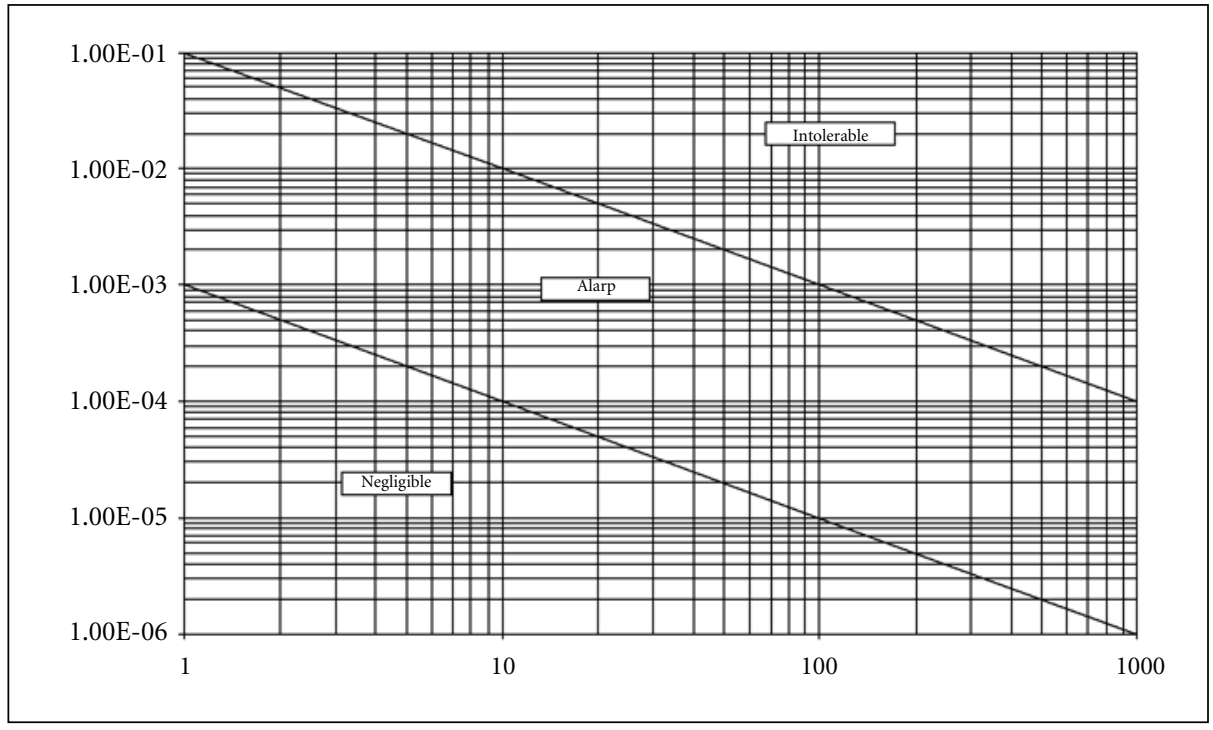

Figure 4. Societal criteria for RoPax vessels

\section{HAZID Results}

SAFEDOR (2006) reports on the outcome of a HAZID session for RoPax. The HAZID session was organised by personnel from LMG Marin (Norway) and The Ship Stability Research Centre and involved personnel from Color Line Marine (Norway), Flensburger Shipyard (Germany), Det Norske Veritas (Norway) and the Maritime and Coastguard Agency (UK). Various RoPax operational phases were considered for which hazards, their causes and consequences were recorded and analysed qualitatively in a structured manner.

A risk register has been developed, comprising the most relevant hazards that may occur in RoPax operations. A total of 58 hazards were identified within the following operational phases:

- Loading (7 hazards);

- Departing quay (8 hazards);

- Transit and navigation in coastal waters (12 hazards);

- Transit in open sea (6 hazards);

- Arriving in port, mooring and preparing for unloading (6 hazards);

- Unloading (6 hazards); 
- Bunkering, treatment of fluid and solid garbage (3 hazards);

- Emergency evacuation and drills (8 hazards);

- Other (2 hazards).

Based on subjective, qualitative estimates of their frequencies and consequences by the HAZID participants, the hazards have been ranked to derive a prioritised list of the most significant hazards. Table 5 contains the top-ranked hazards identified during the HAZID session. Of relevant is also Table 6, containing top-ranked hazards with high frequency of occurrence, but of low consequences.

The HAZID results have confirmed the hazards expected to be significant. In this respect, scenarios initiated by collisions, groundings, fire and flooding from other causes are carried forward for consideration in the risk analysis study of this report.

Table 5. Top-ranked high-consequence hazards

\begin{tabular}{|l|c|c|c|}
\hline Hazard & FI & SI & RI \\
\hline Failure of evacuation equipment during an emergency & 4.78 & 3.33 & $\mathbf{8 . 1 1}$ \\
\hline Fire in accommodation while in open sea or navigating in coastal waters & 3.89 & 4.00 & 7.89 \\
\hline Human error and/or lack of training during an evacuation & 4.56 & 3.22 & 7.78 \\
\hline Collision with other ships while in open sea or navigating in coastal waters & 3.22 & 3.78 & 7.00 \\
\hline Fire on vehicle deck while unloading due to accumulation of fuel spills & 3.33 & 3.22 & $\mathbf{6 . 5 6}$ \\
\hline Fire in machinery spaces while in open sea or navigating in coastal waters & 3.44 & 3.11 & $\mathbf{6 . 5 6}$ \\
\hline Evacuation arrangements and plans not as effective as designed for & 3.44 & 3.11 & $\mathbf{6 . 5 6}$ \\
\hline No or reduced visibility and high toxitity due to smoke during evacuation & 3.00 & 3.33 & $\mathbf{6 . 3 3}$ \\
\hline Evacuating following a fire or explosion & 3.11 & 3.00 & $\mathbf{6 . 1 1}$ \\
\hline Grounding while navigating in coastal waters & 3.22 & 2.89 & $\mathbf{6 . 1 1}$ \\
\hline
\end{tabular}

Table 6. Top-ranked high-frequency hazards

\begin{tabular}{|l|c|c|c|}
\hline Hazard & FI & SI & RI \\
\hline Failure of evacuation equipment during an emergency & 4.78 & 3.33 & $\mathbf{8 . 1 1}$ \\
\hline Collision between a car and the vessel or between two cars during loading & 6.22 & 1.78 & $\mathbf{8 . 0 0}$ \\
\hline Human error and/or lack of training during an evacuation & 4.56 & 3.22 & 7.78 \\
\hline Heavy ship movements due to weather while in open sea & 5.89 & 1.11 & 7.00 \\
\hline Failure of loading equipment (gangways, ramps, cranes, etc.) & 4.67 & 2.11 & $\mathbf{6 . 7 8}$ \\
\hline Own wash effect while navigating in coastal waters & 5.00 & 1.44 & $\mathbf{6 . 4 4}$ \\
\hline Passengers misbehaving & 4.44 & 2.00 & $\mathbf{6 . 4 4}$ \\
\hline Relative movement ship-shore while loading & 4.89 & 1.11 & $\mathbf{6 . 0 0}$ \\
\hline Fire or explosion during loading & 4.33 & 1.56 & $\mathbf{5 . 8 9}$ \\
\hline Bridge equipment generating too much information while navigating & 4.22 & 1.56 & $\mathbf{5 . 7 8}$ \\
\hline
\end{tabular}




\section{Casualty Data Analysis}

This work is based on casualty historical data for the period 1994-2004, obtained by the Lloyds Maritime Information Unit (LMIU) and on fleet statistics for the same period, obtained by Lloyds Register - Fairplay (LMFP). These two sources are considered the most comprehensive for casualty data and fleet-at-risk data, respectively. The reason for the selection of the said period is that the safety assessment study for RoPax vessels carried out as part of the North West European (NWE) Project, DNV Technica (1996a\&b), covered the period 1978-1994, hence providing some reasonable basis of comparison of the corresponding safety records for the two periods.

\subsection{Frequency Analysis}

The LMIU casualty database includes 1,147 incidents for RoPax ships world-wide for the period 1994 to 2004. 54 incidents have happened during repairs or conventions, labour and other disputes, on vessels that were already laid-up or to be broken up (9 incidents for RoPax of 1,000 to 4,000 GRT range and 45 incidents for RoPax of 4,000 GRT and above). These incidents have not been taken into account in the analysis. Also, there were a further 3 incidents which are attributed as acts of terrorism (notably one explosion involving considerable number of fatalities), which have also not been taken into account in the analysis.

A further 42 incidents have happened on RoPax of 100 to 1,000 GRT. These are also excluded from the analysis for the reasons given in Section 3.2, however, given the great number of RoPax ships under 1,000 GRT (1,196 ships according to LRFP data, March 2006), this casualty figure indicates serious under-reporting of casualties.

Casualty records held by LMIU classify incidents as serious and non-serious. An incident is considered as serious if it has involved a single or multiple fatalities, damage to the vessel that has interrupted her service or if the vessel has been lost.

Tables 7, 8 and 9 contain an analysis of the LMIU RoPax casualty data for the period 1994-2004, for RoPax of 1,000 GRT to 4,000 GRT, for RoPax of 4,000 GRT and above and for RoPax of 1,000 GRT and above, respectively.

Other recent studies have also estimated accident frequencies, covering periods similar to the one analysed in this report. More specifically:

- In Vanem and Skjong (2004a) the frequency of collisions for all passenger ships over 4,000 GRT for the period 1990-2000 was estimated as 5.16E-03 per ship year. Table 8 indicates a collision frequency of 1.59E- 02 per ship year, of which only $57 \%$ represent collisions under way, i.e. a frequency of collisions under way of $9.06 \mathrm{E}-03$ per ship year.

- Similarly, Vanem and Skjong (2004a) reports a frequency of groundings for all passenger ships over 4,000 GRT for the period 1990-2000 of 1.03E-02 per ship year. Table 8 above indicates a grounding frequency of $1.13 \mathrm{E}-02$ per ship year.

- Finally, in Vanem and Skjong (2004b) the frequency of serious fires for RoPax over 
5,000 GRT for the period 1990-2002 was estimated as 1.90E-03 per ship year. Table 8 indicates a frequency of $4.18 \mathrm{E}-03$ per ship year.

Taking into account the differences in reporting periods, different samples (importantly the fact that the figures presented in Vanem and Skjong (2004a) refer to all passenger ships, including cruise ships and RoPax) and possibly different definitions of casualty categories and/or the way data are used, it can be considered that fairly agreement exists with results of relevant studies.

Table 7. Number of incidents and drequencies, RoPax 1,000 GRT to 4,000 GRT (1994-2004)

\begin{tabular}{|l|c|c|c|c|c|c|}
\hline \multirow{2}{*}{} & \multicolumn{2}{|c|}{ \# Incidents } & \multirow{2}{*}{ \% Total } & \multirow{2}{*}{$\%$ Serious } & \multicolumn{2}{c|}{ Frequency (per ship year) } \\
\cline { 2 - 3 } \cline { 6 - 7 } & Total & Serious & & & Total & Serious \\
\hline Collision & 53 & 4 & $18.6 \%$ & $8.2 \%$ & $8.01 \mathrm{E}-03$ & $6.04 \mathrm{E}-04$ \\
\hline Contact & 62 & 8 & $21.8 \%$ & $16.3 \%$ & $9.37 \mathrm{E}-03$ & $1.21 \mathrm{E}-03$ \\
\hline Fire/Explosion & 29 & 13 & $10.2 \%$ & $26.5 \%$ & $4.38 \mathrm{E}-03$ & $1.96 \mathrm{E}-03$ \\
\hline Wrecked/Stranded & 48 & 14 & $16.8 \%$ & $28.6 \%$ & $7.25 \mathrm{E}-03$ & $2.11 \mathrm{E}-03$ \\
\hline Hull Damage & 5 & 0 & $1.8 \%$ & $0.0 \%$ & $7.55 \mathrm{E}-04$ & $0.00 \mathrm{E}+00$ \\
\hline Foundered & 0 & 0 & $0.0 \%$ & $0.0 \%$ & $0.00 \mathrm{E}+00$ & $0.00 \mathrm{E}+00$ \\
\hline Machinery damage & 75 & 10 & $26.3 \%$ & $20.4 \%$ & $1.13 \mathrm{E}-02$ & $1.51 \mathrm{E}-03$ \\
\hline Miscellaneous & 13 & 0 & $4.6 \%$ & $0.0 \%$ & $1.96 \mathrm{E}-03$ & $0.00 \mathrm{E}+00$ \\
\hline Total & 285 & 49 & $100.0 \%$ & $100.0 \%$ & $4.31 \mathrm{E}-02$ & $7.40 \mathrm{E}-03$ \\
\hline
\end{tabular}

Fleet at Risk (1994-2004) 6,620

Table 8. Number of incidents and frequencies, RoPax 4,000 GRT and above (1994-2004)

\begin{tabular}{|l|c|c|c|c|c|c|}
\hline \multirow{2}{*}{} & \multicolumn{2}{|c|}{ \# Incidents } & \multirow{2}{*}{$\%$ Total } & \multirow{2}{*}{ \% Serious } & \multicolumn{2}{c|}{ Frequency (per ship year) } \\
\cline { 2 - 3 } & Total & Serious & & & Total & Serious \\
\hline Collision & 141 & 16 & $18.4 \%$ & $12.1 \%$ & $1.59 \mathrm{E}-02$ & $1.81 \mathrm{E}-03$ \\
\hline Contact & 131 & 13 & $17.1 \%$ & $9.8 \%$ & $1.48 \mathrm{E}-02$ & $1.47 \mathrm{E}-03$ \\
\hline Fire/Explosion & 99 & 37 & $12.9 \%$ & $28.0 \%$ & $1.12 \mathrm{E}-02$ & $4.18 \mathrm{E}-03$ \\
\hline Wrecked/Stranded & 100 & 33 & $13.0 \%$ & $25.0 \%$ & $1.13 \mathrm{E}-02$ & $3.73 \mathrm{E}-03$ \\
\hline Hull Damage & 30 & 7 & $3.9 \%$ & $5.3 \%$ & $3.39 \mathrm{E}-03$ & $7.91 \mathrm{E}-04$ \\
\hline Foundered & 2 & 2 & $0.3 \%$ & $1.5 \%$ & $2.26 \mathrm{E}-04$ & $2.26 \mathrm{E}-04$ \\
\hline Machinery damage & 214 & 21 & $27.9 \%$ & $15.9 \%$ & $2.42 \mathrm{E}-02$ & $2.37 \mathrm{E}-03$ \\
\hline Miscellaneous & 50 & 3 & $6.5 \%$ & $2.3 \%$ & $5.65 \mathrm{E}-03$ & $3.39 \mathrm{E}-04$ \\
\hline Total & 767 & 132 & $100.0 \%$ & $100.0 \%$ & $8.67 \mathrm{E}-02$ & $1.49 \mathrm{E}-02$ \\
\hline
\end{tabular}

\begin{tabular}{|l|r|}
\hline Fleet at Risk (1994-2004) & 8,848 \\
\hline
\end{tabular}


Table 9. Number of incidents and frequencies, RoPax 1,000 GRT and above (1994-2004)

\begin{tabular}{|l|c|c|c|c|c|c|}
\hline \multirow{2}{*}{} & \multicolumn{2}{|c|}{ \# Incidents } & \multirow{2}{*}{$\%$ Total } & \multirow{2}{*}{$\%$ Serious } & \multicolumn{2}{c|}{ Frequency (per ship year) } \\
\cline { 7 - 8 } & Total & Serious & & & Total & Serious \\
\hline Collision & 194 & 20 & $18.4 \%$ & $11.0 \%$ & $1.25 \mathrm{E}-02$ & $1.29 \mathrm{E}-03$ \\
\hline Contact & 193 & 21 & $18.3 \%$ & $11.6 \%$ & $1.25 \mathrm{E}-02$ & $1.36 \mathrm{E}-03$ \\
\hline Fire/Explosion & 128 & 50 & $12.2 \%$ & $27.6 \%$ & $8.28 \mathrm{E}-03$ & $3.23 \mathrm{E}-03$ \\
\hline Wrecked/Stranded & 148 & 47 & $14.1 \%$ & $26.0 \%$ & $9.57 \mathrm{E}-03$ & $3.04 \mathrm{E}-03$ \\
\hline Hull Damage & 35 & 7 & $3.3 \%$ & $3.9 \%$ & $2.26 \mathrm{E}-03$ & $4.53 \mathrm{E}-04$ \\
\hline Foundered & 2 & 2 & $0.2 \%$ & $1.1 \%$ & $1.29 \mathrm{E}-04$ & $1.29 \mathrm{E}-04$ \\
\hline Machinery damage & 289 & 31 & $27.5 \%$ & $17.1 \%$ & $1.87 \mathrm{E}-02$ & $2.00 \mathrm{E}-03$ \\
\hline Miscellaneous & 63 & 3 & $6.0 \%$ & $1.7 \%$ & $4.07 \mathrm{E}-03$ & $1.94 \mathrm{E}-04$ \\
\hline Total & 1,052 & 181 & $100.0 \%$ & $100.0 \%$ & $6.80 \mathrm{E}-02$ & $1.17 \mathrm{E}-02$ \\
\hline
\end{tabular}

\begin{tabular}{|l|l|}
\hline Fleet at Risk (1994-2004) & 15,468 \\
\hline
\end{tabular}

\subsection{Comparison with Previous Periods}

A comparison with frequencies calculated in DNV Technica (1996a\&b) referring to North West European experience for the period 1978-1994 is attempted in this section. The following are the points that can be made:

- Collision. The frequency of collisions under way at North West Europe during the period 1978-1994 was 1.32E-02 per ship year. From Table 9 and considering that collisions under way represent only $63 \%$ of the total frequency, the frequency of collisions under way world-wide for the period 1994-2004 is estimated to be 7.88E03 per ship year. This indicates a frequency reduction of $40 \%$.

- Grounding. The frequency of groundings at North West Europe during the period 1978-1994 was 2.00E-02 per ship year. From Table 9, the frequency of groundings world-wide for the period 1994-2004 is estimated to be 9.57E-03 per ship year. This indicates a frequency reduction of $52 \%$.

- Impact. The frequency of impacts at North West Europe during the period 19781994 was 4.90E-02 per ship year. From Table 9, the frequency of impacts worldwide for the period 1994-2004 is estimated to be 1.25E-02 per ship year. This indicates a frequency reduction of $74 \%$.

- Flooding from other causes. Data comparison indicates no chance on this frequency.

- Fire. The frequency of fires at North West Europe during the period 1978-1994 was 1.00E-02 per ship year. From Table 9, the frequency of fires world-wide for the period 1994-2004 is estimated to be 8.28E-03 per ship year. This indicates a frequency reduction of $17 \%$.

- Overall frequency. The overall frequency for all critical scenarios (collisions under way, groundings, impacts, flooding from other causes and fires) at North West Europe during the period 1978-1994 was estimated to be 9.44E-02 per ship year. From Table 9, the overall frequency for these accident scenarios world-wide for the period 
1994-2004 is estimated to be 4.05E-02 per ship year. This indicates an overall frequency reduction of $57 \%$.

Due to differences in reporting (LMIU started systematic collection of casualty data on 1994; before that mainly serious accidents were reported only) the frequency reductions calculated above should be used for reference only. At any case, the calculated reductions provide a concise indication that safety records have improved during the period 1994-2004.

\subsection{Potential Loss of Life}

Table 11 contains a list of the 14 fatal incidents occurred world-wide during the period 1994-2004. The fatalities data from this list have been used to produce the F-N curve presented in Figure 5.

It is noted that this set of data does not include the al-Salam Boccaccio 98 incident, which happened on 3 February 2006 with around 1,000 fatalities. Including this incident in a PLL calculation for the period 1994-2006, we obtain a figure of 1.35E-01 per ship year.

Table 10. PLL, RoPax 1,000 GRT and above, 1994-2004

\begin{tabular}{|l|c|c|c|c|}
\hline & \# Incidents & \# Fatalities & PLL (per ship year) & $\%$ \\
\hline Collision & 2 & 7 & $4.53 \mathrm{E}-04$ & $0.5 \%$ \\
\hline Fire/Explosion & 8 & 378 & $2.44 \mathrm{E}-02$ & $25.6 \%$ \\
\hline Wrecked/Stranded & 1 & 94 & $6.08 \mathrm{E}-03$ & $6.4 \%$ \\
\hline Hull Damage & 3 & 995 & $6.43 \mathrm{E}-02$ & $67.5 \%$ \\
\hline Total & 14 & 1,474 & $9.53 \mathrm{E}-02$ & $100.0 \%$ \\
\hline
\end{tabular}

\begin{tabular}{|l|l|}
\hline Fleet at Risk (1994-2004) & 15,468 \\
\hline
\end{tabular}

\section{$7 \quad$ Risk Model}

\subsection{Description of the Model}

This section describes the high-level risk model for RoPax operations. The risk model comprises event trees containing potential outcomes for the following initiating events:

1. Collision

2. Grounding (incidents classified by LMIU as "wrecked/stranded")

3. Impact (incidents classified by LMIU as "contact")

4. Other flooding (incidents classified by LMIU as "hull damage" or "foundered")

5. Fire/explosion

This selection of initiating events is in agreement with the outcome of the HAZID work (described in Section 5). As it can be seen from the frequency analysis of Section 6, 
these initiating events provide a sufficient basis for the derivation of a complete risk profile for RoPax operations, since:

Table 11. RoPax fatal incidents, world-wide, period 1994-2004

\begin{tabular}{|c|c|c|c|c|c|}
\hline Incident Date & Vessel & Year Built & Event & $\begin{array}{c}\text { Incident } \\
\text { Location }^{1}\end{array}$ & Fatalities \\
\hline 18.05 .1994 & Al-Qamar Al-Saudi Al-Misri & 1970 & Fire/Explosion & RED & 21 \\
\hline 28.06 .1994 & Tag Al Salam & 1969 & Fire/Explosion & BAL & 1 \\
\hline 28.09 .1994 & Estonia & 1980 & Flooding & BAL & 852 \\
\hline 18.09 .1998 & Princess of the Orient & 1974 & Flooding & SCH & 94 \\
\hline 01.11 .1999 & Spirit of Tasmania II & 1988 & Fire/Explosion & EME & 14 \\
\hline 25.11 .1999 & Dashun & 1983 & Fire/Explosion & SCH & 282 \\
\hline 23.12 .1999 & Asia South Korea & 1972 & Fire/Explosion & SCH & 56 \\
\hline 16.07 .2000 & Ciudad de Ceuta & 1975 & Collision & WME & 6 \\
\hline 17.08 .2000 & Gurgen 2 & 1966 & Fire/Explosion & EME & 1 \\
\hline 26.09 .2000 & Express Samina & 1966 & Grounding & EME & 94 \\
\hline 22.06 .2002 & Al Salam Petrarca 90 & 1971 & Fire/Explosion & RED & 1 \\
\hline 11.08 .2002 & Tacloban Princess & 1970 & Fire/Explosion & SCH & 2 \\
\hline 22.10 .2002 & Mercuri 2 & 1984 & Flooding & EME & 49 \\
\hline 01.07 .2003 & Paglia Orba & 1994 & Collision & WME & 1 \\
\hline
\end{tabular}

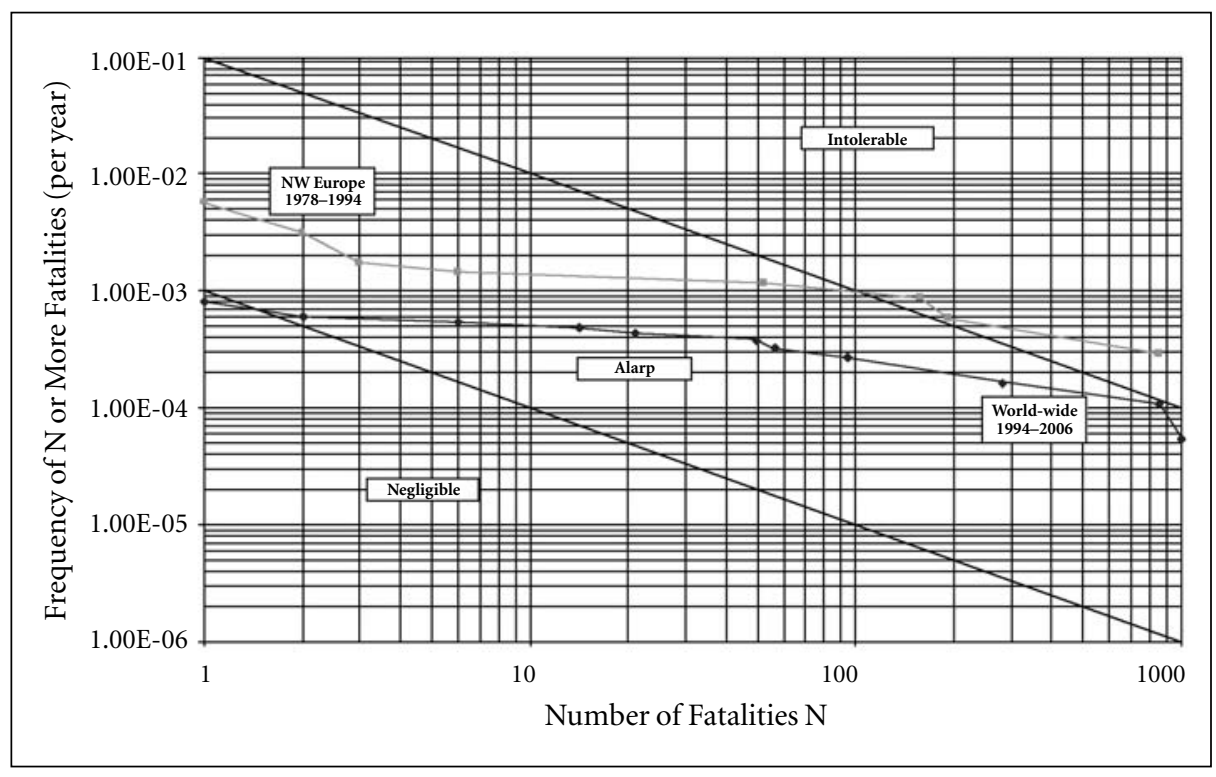

Figure 5. RoPax F-N Curve (Historical Risk)

1 Location of Casualty: BAL - Baltic; EME - East Mediterranean and Black Sea; ED - Red Sea; $\mathrm{SCH}$ - South China, Indochina, Indonesia and Philippines; WME - West Mediterranean 
- All fatal incidents were initiated by one of these causes as shown on Tables 10 and 11; also in previous relevant studies, for example Aldwinckle and Prentice (1990) and DNV Technica (1996a\&b).

- These five initiating causes represent $66.5 \%$ of all incidents and $81.2 \%$ of serious incidents recorded for the period 1994-2004 (Table 9). This is mainly due to the fact that incidents recorded as "machinery damage/failure" are not taken forward for further analysis and elaboration. Incidents recorded as such by LMIU did not develop to any subsequent accident of the five categories mentioned above. Extended time off-service for repair is the reason LMIU recorded a number of "machinery damage/failure" incidents as serious.

Potential outcomes (accident scenarios) for the five initiating events taken forward for analysis are based on the analysis carried out in the safety assessment study of the Joint North West European project (DNV Technica 1996a\&b). Since the risk model required by this study is at a high-level, this previous work is sufficient for this purpose.

For clarity, definitions for the five initiating events considered within the high-level risk model are as follows, adopting the accident classification of DNV Technica (1996a$\& \mathrm{~b})$ :

- Collisions: events where two vessels accidentally come into contact with each other. This may lead to sinking, grounding or to a fire on the vessel, but these are counted as collisions if this was the cause. This definition includes collisions between two ships under way, and also events sometimes known as "strikings", where a moving ship strikes another ship at a berth.

- Groundings: cases where a vessel comes into contact with the sea bed or shore, including underwater wrecks. If the ship is struck fast, this is known as "stranding". If the ship sinks, this is sometimes known as "wreck". The category "wreck/stranded" used by LMIU is equivalent to the term "grounding" used in this study.

- Impacts: cases where a vessel comes into contact with objects other than ships, the sea bed or the shore. This includes impacts on berths, bridges and offshore platforms. It is known by LMIU as "contact".

- Other flooding: cases where water enters a ship for reasons other than collision, impact or grounding (treated separately). Some of these events are included by LMIU under the category "hull/machinery damage". If the ship sinks, this is known by LMIU as "foundering". The "other flooding" category is also taken to include weather damage, cargo shifting and intact instability events which would lead to flooding if the ship were to sink.

- Fire/explosion: cases where fires and/or explosions occur for reasons other than collision, impact or grounding (treated separately).

The Appendix contains the five event trees (Figures A.1 to A.5) put together for the high-level risk model. The branch probabilities have been derived using data available and reflect possible outcomes following collisions, groundings, impacts, flooding from other causes and fires. 


\subsection{Summary Calculations}

Table 12 summarizes the risk calculations carried out on the basis of the risk model.

The individual risk calculated by the risk model is $2.61 \mathrm{E}-04$ per year, assuming the vessel being at sea and a person being onboard for the full duration of the year, as recorded in Table 12. To provide an estimate of the individual risk experienced by crew members and passengers, the following considerations can be made:

- For crew members: assuming a 50-50 rotation scheme and that the vessel is at sea half of each day, the model predicts an overall individual risk for crew of 6.52E-05 per year. If we assume 3 crews rotating on a vessel (this is not a widespread practice, but is valid for some crew positions onboard a RoPax) then the overall individual risk becomes $4.34 \mathrm{E}-05$ per year.

- For passengers: a passenger that spends 1 week per year travelling onboard a RoPax, experiences an individual risk 5.01E-06 per year. For a RoPax sailing at sea for 12 hours per trip, the assumption of 1 week per year means that the passenger takes 7 return journeys a year. Considering a passenger that makes 1 such return trip a week, the individual risk becomes 3.72E-05 per year (this estimation may be appropriate for a truck driver that travels regularly on a RoPax route).

Considering the figures above, it can be concluded that individual risk levels are within the ALARP region for both passenger and crew members.

Figure 6 presents the F-N curve calculated by the risk model.

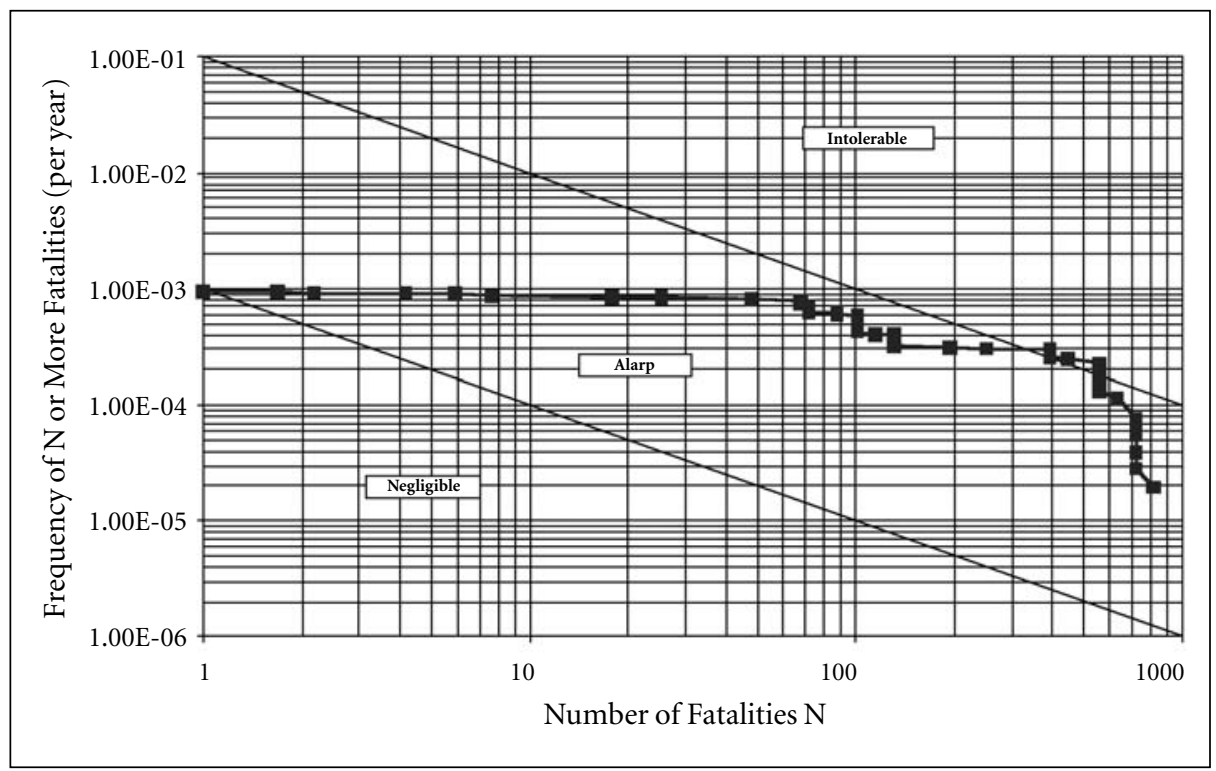

Figure 6. F-N curve, risk model, RoPax 1,000GRT and above, world-wide, 1994-2004 
Table 12. Risk calculations, RoPax 1,000 GRT and above, world-wide, period 1994-2004

\begin{tabular}{|l|c|c|c|c|c|c|}
\hline & $\begin{array}{c}\text { Frequency } \\
\text { (per ship year) }\end{array}$ & $\begin{array}{c}\text { Frequency } \\
(\%)\end{array}$ & $\begin{array}{c}\text { Ind. Risk } \\
\text { (per year) }\end{array}$ & $\begin{array}{c}\text { PLL } \\
\text { (per ship year) }\end{array}$ & $\begin{array}{c}\text { PLL } \\
(\%)\end{array}$ & $\begin{array}{c}\text { Fatalities } \\
\text { (per year) }\end{array}$ \\
\hline Collision & $1.25 \mathrm{E}-02$ & $28 \%$ & $2.75 \mathrm{E}-05$ & $2.34 \mathrm{E}-02$ & $11 \%$ & 31 \\
\hline Grounding & $9.57 \mathrm{E}-03$ & $21 \%$ & $3.02 \mathrm{E}-05$ & $2.57 \mathrm{E}-02$ & $12 \%$ & 23 \\
\hline Impact & $1.25 \mathrm{E}-02$ & $28 \%$ & $1.63 \mathrm{E}-06$ & $1.39 \mathrm{E}-03$ & $1 \%$ & 2 \\
\hline Flooding & $2.39 \mathrm{E}-03$ & $5 \%$ & $1.31 \mathrm{E}-04$ & $1.12 \mathrm{E}-01$ & $50 \%$ & 148 \\
\hline Fire & $8.28 \mathrm{E}-03$ & $18 \%$ & $7.00 \mathrm{E}-05$ & $5.95 \mathrm{E}-02$ & $27 \%$ & 79 \\
\hline Total & $4.52 \mathrm{E}-02$ & $100 \%$ & $2.61 \mathrm{E}-04$ & $2.22 \mathrm{E}-01$ & $100 \%$ & 282 \\
\hline
\end{tabular}

\section{Risk Control Options}

On the conclusion of risk analysis it is necessary to decide upon a series of actions that will prevent and/or mitigate the harmful effects of the identified risks. That is, a list of Risk Control Options (RCOs). The contribution of each RCO will be assessed against the benefit it offers and the cost to implement it. The Gross Cost of Averting a Fatality (GrossCAF) and the Net Cost of Averting a Fatality (NetCAF) indices are used for this task. They are defined as follows (IMO 2002):

GrossCAF $=\frac{\Delta \mathrm{C}}{\Delta \mathrm{R}}$ and NetCAF $=\frac{\Delta \mathrm{C}-\Delta \mathrm{B}}{\Delta \mathrm{R}}$

- $\Delta \mathrm{C}$ : the cost per ship of RCO;

- $\triangle \mathrm{B}$ : the economic benefit per ship, resulting from the implementation of each RCO;

- $\triangle \mathrm{R}$ : the risk reduction (number of lives saved) per ship, resulting from the implementation of each RCO.

The selection of the appropriate list of RCOs should reflect the nature of operation of the ship under study and it focus on the findings of the risk analysis. That is, bearing in mind that collision frequency is at least 1.5 times higher that the rest, special attention should be paid to the navigational issues and procedures for averting hazards the might lead to such an outcome. These RCO are naturally concerned with navigational systems and the contribution of human element.

Under this perspective, the RCOs list identified in IMO (2004) was adopted in this study with all the relevant modifications to reflect the operational risks of RoPax vessels. As such, the following list is representative of the final RCOs considered here:

- Safety and security centre on board the ship;

- Implementation of a series of navigational aids like Electronic Log Book (ELB), Electronic Chart Display System (ECDIS), Automatic Identification System (AIS);

- Duplication of navigational systems for increasing reliability;

- Etc. 
When considering the human element in potentially hazardous and unwanted situations, then the RCOs list was extended further to include:

- A second officer on watch;

- Improvement in the training procedures of navigators;

- Implementation of Bridge Resource Management (BRM);

- Etc.

Except navigational-related risks, due attention should be paid to the rest of the identified risks by selecting appropriate RCO which reflect the operational profile of the vessel under consideration. It should be mentioned here that the FSA study at this stage is heavily supported by expert judgment. As such, the views and experience of the expert panel are manifested by extending further the existing RCOs list by hazards related to the whole range of operations like:

- Bunkering;

- Oil leakage of fuel mains and fire prevention;

- Electrical fires;

- Etc.

All these RCOs can be accommodated under the fire risk category.

The final step of this phase of the FSA study is to assess the potential contribution of each RCO in terms of its NetCAF index. This would entail two distinct elements: (i) access to commercial information, operational data and costs for the calculation of the implementation cost of each RCO, (ii) establishment of the measure of benefit when human lives was the point of interest (other than just material or property damage due to an unwanted event).

In the first case, consultancy with marine operators provided the required data along with important operational experience regarding the soundness of application for each RCO. The cost for implementation was calculated based on the conventional Net Present Value (NPV) approach according to the formula:

$N P V=C+\sum_{j=1}^{N} \frac{A}{(1+i)^{j}}$

Where:

$\mathrm{C}$ is the initial amount spent for each RCO

A is the annual cost for each RCO (e.g. maintenance)

$\mathrm{i}$ is the interest rate

$\mathrm{N}$ is the number of periods

The other remaining element has to do with the cost of human life. There has been too much debate on this admittedly complicated issue but it was decided to comply 
with IMO guidelines, SAFEDOR (2005) and IMO (2000), and set this value to 3 million USD.

Considering all the above information, it becomes obvious that if the cost of implementing an RCO is less than the gained benefit (i.e. $\Delta \mathrm{C}-\Delta \mathrm{B}<0$ ), then this RCO should be adopted in practice. In this particular study this was the case for improving the human intervention in the operation and the adoption of a series of navigational aids like ECDIS, AIS, ELB, etc.

\section{Conclusions}

The main conclusions of the study are the following:

- The frequency of any collision, grounding, impact, flooding from other causes or fire/explosion incident happening is 4.52E-02 per ship year ( 1 in 22 ship years; world-wide casualty data, 1994-2004). This breaks down as collision (28\%), grounding (21\%), impact (28\%), flooding from other causes (5\%) and fire/explosion (18\%).

- The frequency of a serious collision, grounding, impact, flooding from other causes or fire/explosion incident happening is 9.50E-03 per ship year ( 1 in 105 ship years; world-wide casualty data, 1994-2004). This breaks down as collision (14\%), grounding (32\%), impact (14\%), flooding from other causes (6\%) and fire/explosion (34\%).

- These values are in general agreement with other published studies, covering periods contemporary to that of this study.

- There is significant reduction in the frequency of incidence occurrence. As an indication, comparison of the data above with data of the North West European Project on the Safety of RoPax ships (period 1978-1994) shows a reduction of 40\% of collision frequency, $52 \%$ on grounding frequency, $74 \%$ on impact frequency, $17 \%$ on fire/explosion frequency and $57 \%$ on the overall frequency of these events.

- During the period 1994-2004 there have been 14 fatal incidents, resulting in 1,474 fatalities. The corresponding Potential Loss of Life is 9.53E-02 per ship year (approximately 134 fatalities per year). The figure is dominated by incidents involving flooding from other causes $(67.5 \%$ of fatalities), followed by fire/explosion $(25.6 \%)$ and grounding incidents $(6.4 \%)$.

- Comparison on the F-N curve of the PLL for the period 1994-2004 world-wide with North West European experience for the period 1978-1994, demonstrates a considerable risk reduction, however, it also demonstrates that risk is still high at the ALARP region (Figure 5).

- Frequency and consequences reductions indicate an improving safety record of the RoPax fleet world-wide. This can be attributed to the application of contemporary rules and regulation and implementation of robust safety procedures in operating the vessels. However, risks are still high at the ALARP region, indicating more measures need to be taken.

- A high-level risk model is proposed, which includes a number of potential outcomes, considered to represent sufficiently the risk profile of RoPax operations. Section 7 of the report provides the details of the model, its results presented in Table 12 and Figure 6. 
- Probabilities for the various accident scenarios considered were derived from accident experience of the period 1994-2004 and where this was not sufficient these predictions were based on previous studies (accident experience from earlier periods, relevant calculations or judgement). However, use of expert judgement was kept to a minimum.

- Risks are found to be high at the ALARP region, indicating the need for further risk control options to be assessed and recommended.

- Uncertainties in using the model refer mainly to the average fatality rates used for the various accident scenarios considered. In this study, these are based solely on past actual experience with RoPax vessels. This has proven inevitable, since no other feasible alternative was available for the wide range of accident scenarios considered.

\section{Acknowledgements}

The work reported in this paper has been carried out under the SAFEDOR project, IP-516278, with partial funding from the European Commission. The opinions expressed are those of the authors and should not be construed to represent the views of the SAFEDOR partnership.

\section{References}

Aldwinckle, D.S. and D. Prentice. 1990. The Safety Record and Risk Analysis of Ro-Ro Passenger Ferries. Proceedings of the International Symposium on The Safety of Ro-Ro Passenger Ships, 26-27 April, London, $20 \mathrm{p}$.

DNV Technica. 1996a. Safety Assessment of Passenger Ro-Ro Vessels. Main Report (Document Number: REP-T09-003), Joint North West European Project, 28.10.1996.

1996b. Safety Assessment of Passenger Ro-Ro Vessels. Appendices (Document Number: REP-T09-003A), Joint North West European Project, 28.10.1996.

Kanerva, M. 2001. From Handy Size up to Large Cruise Ferries, elements required to design and build successful configurations. Proceedings of the Euro-Conference on Passenger Ship Design, Construction, Safety and Operation. October 2001, Crete, 83112.

International Maritime Organization (IMO), Maritime Safety Committee (MSC). 2000. Formal Safety Assessment: Decision Parameters including Risk Acceptance Criteria. MSC72/16, Submitted by Norway. London: IMO.

2002. Guidelines for Formal Safety Assessment (FSA) for use in the IMO rulemaking process. MSC/Circ.1023. London: IMO.

2004. Large Passenger Ship Safety: FSA Study on Navigational Safety of Passenger Ships. MSC 78/4/2, 6 February 2004, Submitted by Norway. London: IMO. 
SAFEDOR. 2005. Risk Evaluation Criteria. SAFEDOR Deliverable D4.5.2.

2006. HAZID for RoPax. SAFEDOR Deliverable D4.2.1.

Vanem, E. and R. Skjong. 2004a. Collision and Grounding of Passenger Ships - Risk Assessment and Emergency Evacuations, Proceedings of the $3^{\text {rd }}$ International Conference on Collision and Grounding of Ships. ICCGS 2004. October, Izu, Japan, 195-202.

2004b. Fire and Evacuation Risk Assessment for Passenger Ships. Proceedings of the $10^{\text {th }}$ International Conference on Fire Safety and Engineering, INTERFLAM 2004. July, Edinburgh, UK, 365-374. 


\section{Appendix}

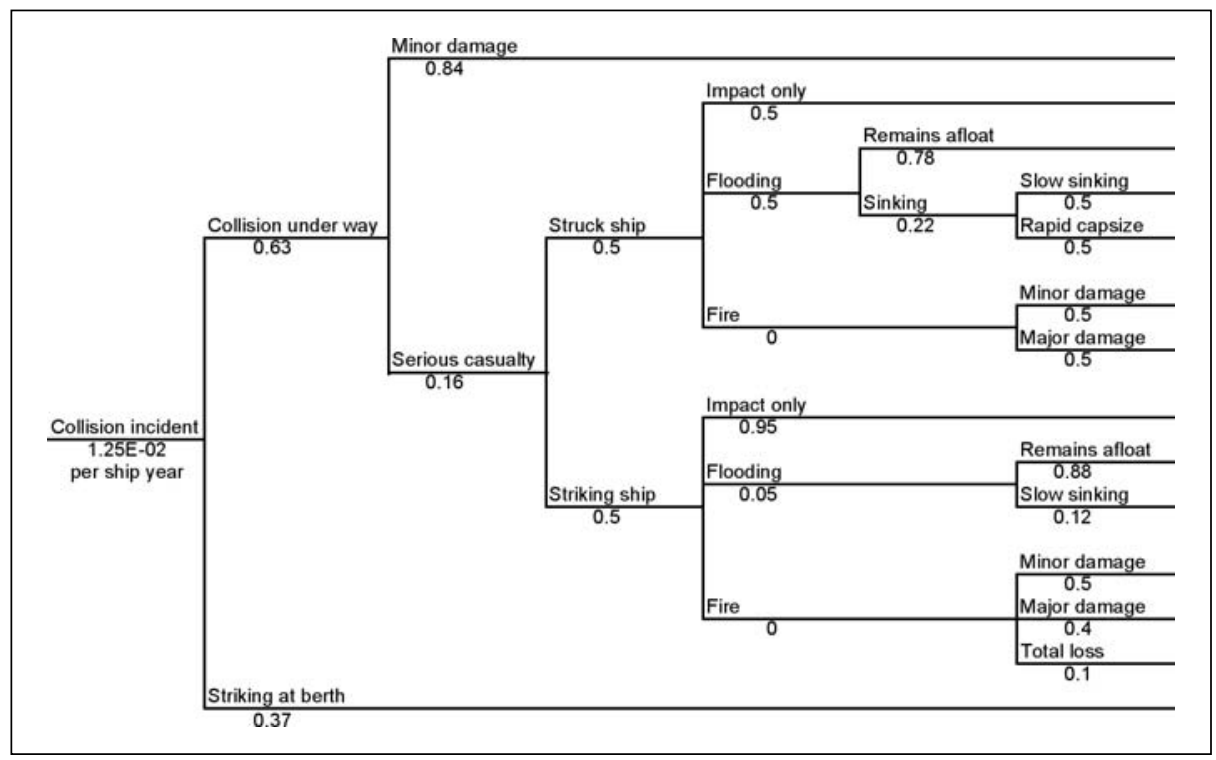

Figure A.1. Generic collision event tree (world-wide experience, 1994-2004)

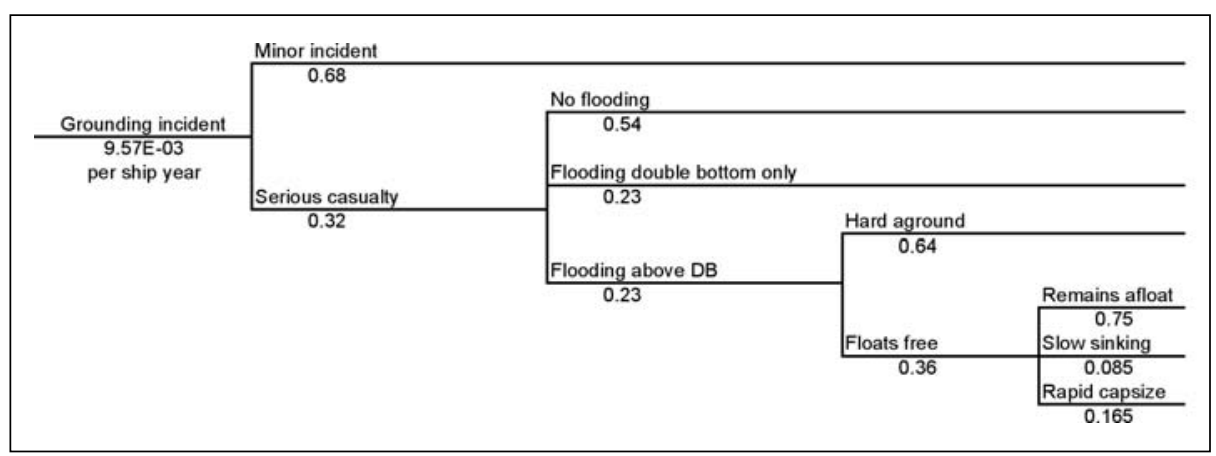

Figure A.2. Generic grounding event tree (world-wide experience, 1994-2004)

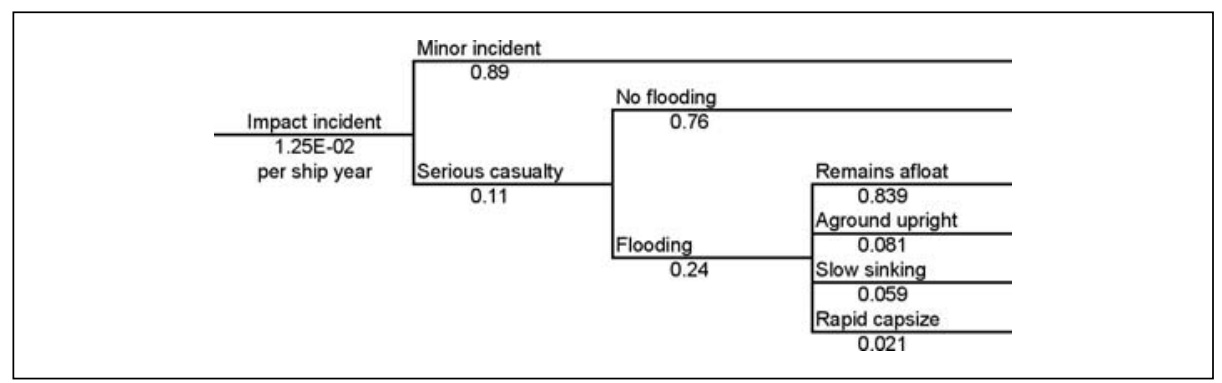

Figure A.3. Generic impact event tree (world-wide experience, 1994-2004) 


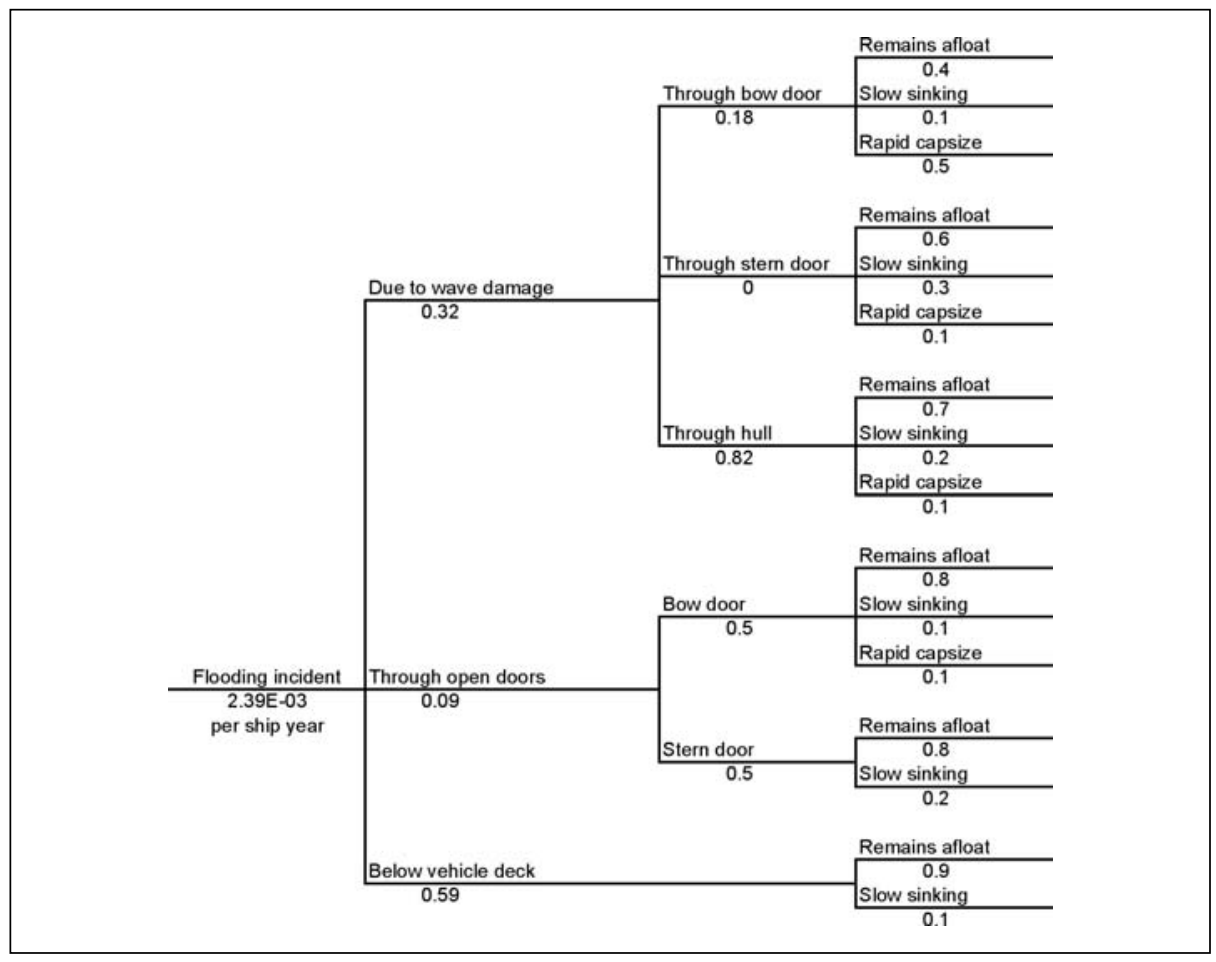

Figure A.4. Generic flooding event tree (world-wide experience, 1994-2004)

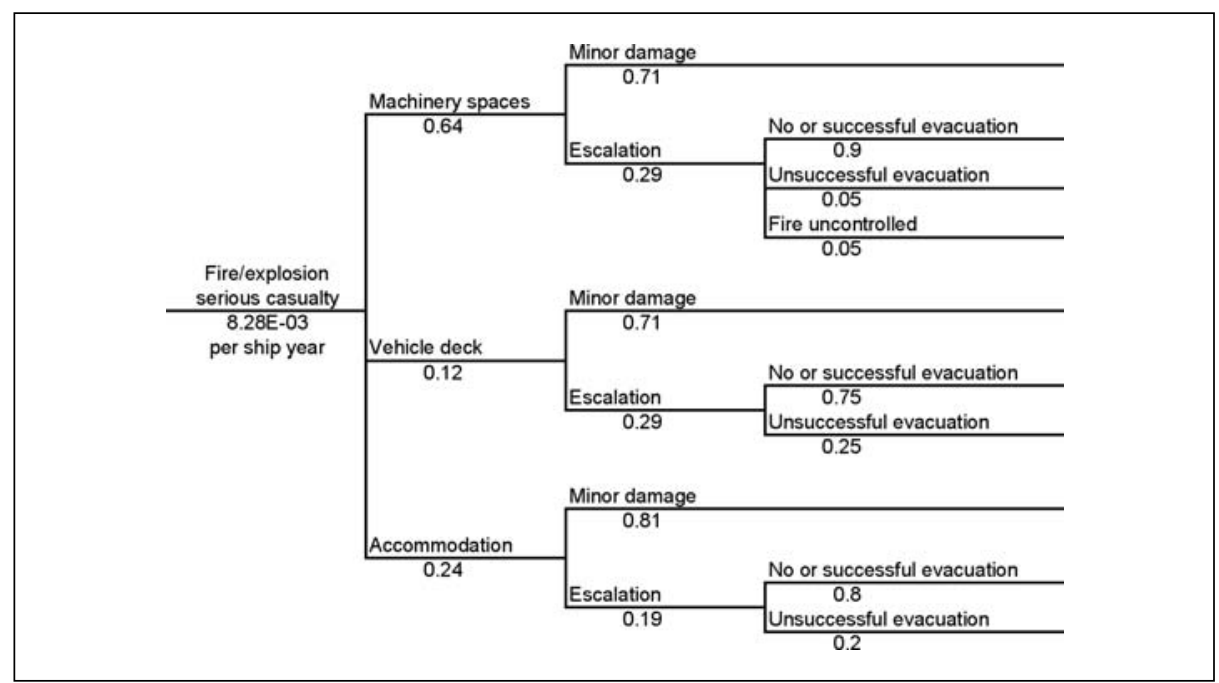

Figure A.5. Generic fire event tree (world-wide experience, 1994-2004) 